\title{
A model-based approach for current voltage analyses to quantify degradation and fuel distribution in solid oxide fuel cell stacks
}

\author{
Markus Linder ${ }^{\mathrm{a}, \mathrm{b}, *}$, Thomas Hocker ${ }^{\mathrm{a}}$, Christoph Meier $^{\mathrm{a}}$, Lorenz Holzer ${ }^{\mathrm{a}}$, K. Andreas Friedrich ${ }^{\mathrm{b}}$, Boris Iwanschitz , $^{\mathrm{c}}$ \\ Andreas Maic ${ }^{\mathrm{c}}$ J. Andreas Schuler ${ }^{\mathrm{c}}$ \\ ${ }^{a}$ ZHAW Zurich University of Appl. Sciences, Institute of Computational Physics, Technikumstrasse 9, CH-8401 Winterthur, Switzerland \\ ${ }^{b}$ Deutsches Zentrum für Luft- und Raumfahrt, Institut für Technische Thermodynamik, Pfaffenwaldring 38-40, D-70569 Stuttgart, Germany \\ ${ }^{c}$ Hexis AG, Zum Park 5, CH-8404 Winterthur, Switzerland
}

\begin{abstract}
Reliable quantification and thorough interpretation of the degradation of solid oxide fuel cell (SOFC) stacks under real conditions is critical for the improvement of its long-term stability. The degradation behavior is often analyzed based on the evolution of current-voltage (V,I) curves. However, these overall resistances often contain unavoidable fluctuations in the fuel gas amount and composition and hence are diffcult to interpret. Studying the evolution of internal repeat unit $(\mathrm{RU})$ resistances is a more appropriate measure to assess stack degradation. RU-resistances follow from EIS-data through subtraction of the gas concentration impedance from the overall steady-state resistance. In this work a model-based approach where a local equilibrium model is used for spatial discretization of a SOFC stack RU running on hydrocarbon mixtures such as natural gas. Since under stack operation, fuel leakages, uneven fuel distribution and varying natural gas composition can influence the performance, they are taken into account by the model. The model extracts the time-dependent internal resistance from (V,I)-data and local species concentration without any fitting parameters. RU resistances can be compared with the sum of the resistances of different components that allows one to make links between laboratory degradation experiments and the behavior of SOFC stacks during operation.
\end{abstract}

Keywords: solid oxide fuel cell (SOFC), current voltage characteristic, stack degradation, fuel distribution, hydrocarbon fuels, local thermodynamic equilibrium

\section{Introduction}

For commercially available stationary solid oxide fuel cell (SOFC) applications a lifetime of at least $40,000 \mathrm{~h}$ with a power degradation lower than $1 \%$ per $1000 \mathrm{~h}$ are required [1-5]. To meet these goals the performance of SOFC stacks needs to be monitored during operation and the obtained results need to be properly interpreted [6].

Stack performance data can be used to identify operation errors and irregularities such as changes in the fuel supply. Performance data are often extrapolated over time to make predictions regarding the stack life-time. However, to get the maximum benefit from stack performance data combined experimental and theoretical methods have to be applied.

\footnotetext{
*Corresponding author. Tel.: +41 58934 7717; Fax: +41 58934 7797

Email address: markus. linder@zhaw.ch (Markus Linder)
}

Performance losses are generally characterized by monitoring an operation parameter such as current, voltage or power or by current-voltage (V,I) data analysis at different time steps [7-12]. The main parameters extracted from (V,I)-curves are open circuit voltages $(\mathrm{OCV})$ and overall area specific resistances $\left(\mathrm{ASR}_{\mathrm{tot}}\right)$ of a individual or all repeat unit(s) (RU) $[8,13]$. Ideally the $\mathrm{ASR}_{\text {tot }}$ obtained from (V,I)-data of the stack can be correlated with partial resistances of local degradation phenomena, that are most suitably studied in button cell or other laboratory experiments. However, the $\mathrm{ASR}_{\text {tot }}$ is affected by fuel gas effects which make comparisons with partial resistances difficult. In addition, these fuel gas effects show fluctuations resulting from fuel leakages, unequal fuel distribution between the different repeat units within the stack and unavoidable variations in the fuel composition provided by the natural gas from the local grid. As a result, experimental (V,I)-data from SOFC stacks operated e. g. with natural gas from the local grid often shows significant scatter. Variations in the 
observed degradation data can happen from one stack to another and within a single stack from one RU to another [13, 14]. Deviations between the measured and theoretical OCVs for example can be related to unusual fuel reformer operation or fuel leakages that affect the anode and/or cathode gas composition by direct oxidation of a certain amount of fuel and air upstream to the RU, respectively $[13,15,16]$. In addition, deviations in the $(\mathrm{V}, \mathrm{I})$-characteristic can be related to the overall amount of fuel available [13]. This can be affected by unequal fuel distribution between the different repeat units of a single stack e. g. by manufacturing and assembling tolerances. It can also be caused by fuel leakages $[17,18]$ (e. g. by cracks and sealing points) and by sensor malfunctions such as drifts in the output of upstream located thermal mass flow controllers [19]. Furthermore, the overall temperature level and the temperature distribution over the stack both can vary and therefore cause additional scatter in observed stack performances. This is because temperature influences the cell potential, but also ohmic and polarization losses [20, 21]. Note however that recent advances in the thermal management of SOFC stacks led to well controllable and rather homogeneous stack temperatures $[16,22]$. Fuel gas effects are often the main cause for deviations from normal stack behavior for the Hexis SOFC stack. The separation of fuel gas effects from the "true", internal resistance of a stack repeat unit $\left(\mathrm{ASR}_{\mathrm{RU}} \neq \mathrm{ASR}_{\text {tot }}\right)$ can be accomplished by electrochemical impedance spectroscopy (EIS) shown in section 2 [13, 23, 24]. However, EIS measurements are generally not available for SOFC stacks running in the field. There is hence a need for extracting internal stack repeat unit resistances from commonly available, time-dependent $(\mathrm{V}, \mathrm{I})$-data, to accurately predict and interpret the performance of SOFC stacks under real conditions (using e.g. natural gas as fuel).

A method for extracting $\mathrm{ASR}_{\mathrm{RU}}$ from (V,I)-data has already been published earlier by the authors [11]. There a 0D thermodynamic equilibrium model assuming a uniform distribution of fuel and air over the entire $\mathrm{RU}$ to calculate $\mathrm{ASR}_{\mathrm{gas}}$ for hydrocarbon-containing fuels is used [25].If this 0D-approach is applied to fuel cells with an active cell area of several square centimeters, e. g. $100 \mathrm{~cm}^{2}$, the calculated gas concentration resistance $\mathrm{ASR}_{\text {gas }}$ is significantly overestimated. Such a deviation is obvious, since the fuel composition and oxygen partial pressure variations along the gas channels between corresponding inlet and outlet is not considered in a 0D-approach.

In this work we propose a model-based approach to extract repeat unit resistances $\mathrm{ASR}_{\mathrm{RU}}$ from experimen- tal (V,I)-data without using any fitting parameters. The model separates internal ohmic and polarization losses from fuel gas concentration effects and takes into account different types of fuel leakages and possible fluctuations in the fuel gas composition from the grid. The comparison of time dependent $\mathrm{ASR}_{\mathrm{RU}}$ evolution during stack operation with averaged ASR trends obtained from single experiments under laboratory conditions has a number of applications. It allows one to verify if the degradation phenomena observed in single experiments under laboratory conditions can explain the degradation behavior within stacks using the same components. The model enables furthermore to extract local species concentration in the flow channels as well as local current densities and potentials for a given fuel utilization (FU).

\section{Conceptual approach}

Depending on the cell and stack design, $\mathrm{ASR}_{\mathrm{RU}}$ includes the contributions of the different RU layers and their mutual interfaces. For Hexis stacks based on electrolyte-supported cells (ESCs) including metallic interconnects (MICs), the main contributions comprise ohmic losses $\left(\mathrm{ASR}_{\mathrm{ohm}}\right)$ from the electrolyte $\left(\mathrm{ASR}_{\mathrm{el}}\right)$, contact resistances $\left(\mathrm{ASR}_{\mathrm{con}}\right)$ and oxide layers formed on metallic interconnect as well as ohmic and polarization losses from the electrodes $\left(\mathrm{ASR}_{\mathrm{an}}, \mathrm{ASR}_{\mathrm{ca}}\right)$.

Electrochemical impedance spectroscopy (EIS) enables to separate internal repeat unit resistances $A_{S R}$ from gas concentration losses $\left(\mathrm{ASR}_{\mathrm{gas}}\right)$ since the overall resistance is defined as follow:

$$
\mathrm{ASR}_{\mathrm{tot}}=\mathrm{ASR}_{\mathrm{RU}}+\mathrm{ASR}_{\mathrm{gas}} .
$$

Fig. 1 shows impedance data for one repeat unit in a 5-cell Hexis stack operated at $900{ }^{\circ} \mathrm{C}$ with catalytic partial oxidized (CPOx) reformed natural gas. The mass flux of natural gas was varied between 2 and $6 \mathrm{~g} \mathrm{~h}^{-1}$. Fig. 1a presents the EIS-data in a Nyquist plot. Variations of the fuel amount basically affects the gas concentration arc in the low frequency region $(<0.5 \mathrm{~Hz})$ on the right whereby this arc is scaled-down with increasing fuel amount. For a large surplus of fuel, typically delivered in button cell experiments, the gas concentration arc disappears since gas concentration losses are inverse proportional to the fuel feed [25-27]. Furthermore fuel variations have a negligible impact on the electrode resistances $\mathrm{ASR}_{\mathrm{an}}$ and $\mathrm{ASR}_{\mathrm{ca}}$ compared to the overall resistance $\mathrm{ASR}_{\text {tot }}$. This behavior is also representative for other stacks with different cell types at OCV [21, 28, 29]. 
The internal resistance $\mathrm{ASR}_{\mathrm{RU}}$ extracted from EIS-data consist of the ohmic resistances $\mathrm{ASR}_{\mathrm{ohm}}$, at the high frequency intercept in the Nyquist plot (Fig. 1a), and the electrode losses $\mathrm{ASR}_{\mathrm{an}}$ and $\mathrm{ASR}_{\mathrm{ca}}$ represented by the two smaller not fully formed arcs in the frequency range $>0.5 \mathrm{~Hz}$. Effects of the fuel amount variations are also shown in Fig. 1b whereby $\operatorname{Im}(Z)$-part is plotted against the frequency. Variations related to electrodes processes are identifiable in the frequency range $>0.5 \mathrm{~Hz}$.

a
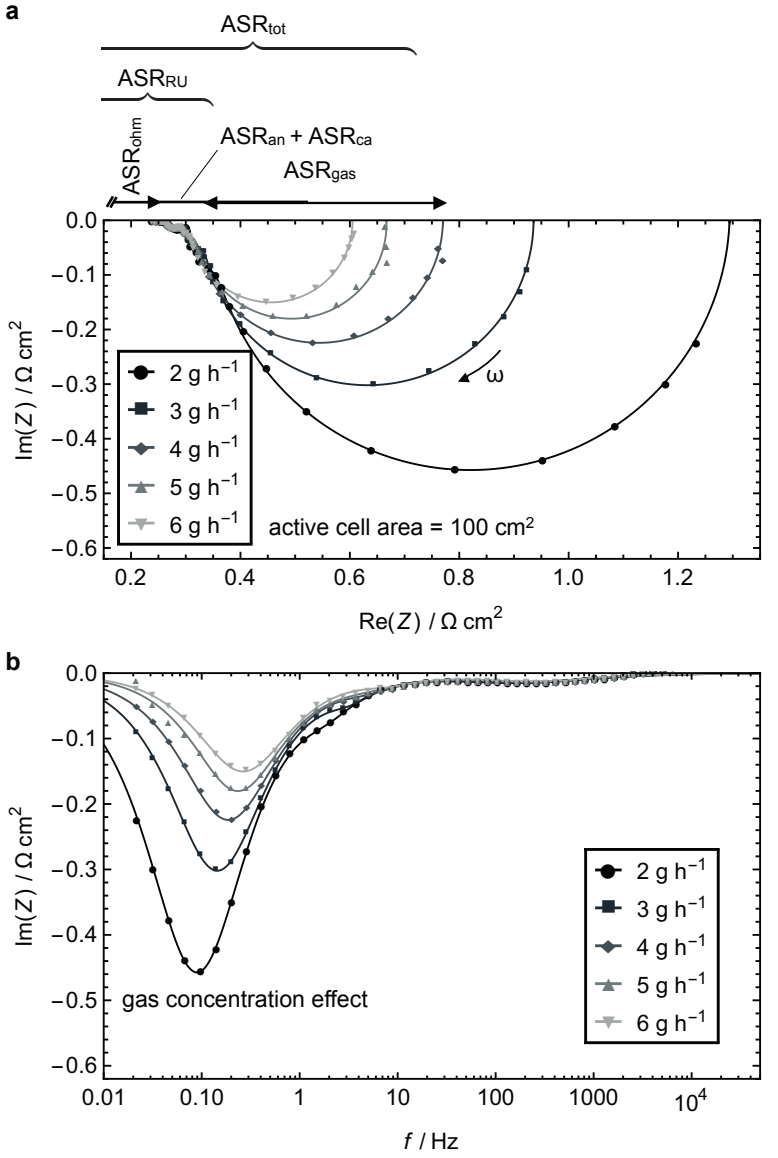

Figure 1: EIS data from a Hexis cell $\left(100 \mathrm{~cm}^{2}\right)$ operated in five cell stack at $900{ }^{\circ} \mathrm{C}$ with $\mathrm{CPOx}$ reformed natural gas for varying fuel amounts at $\approx 50 \%$ FU. a) Nyquist diagram including the interpretation of the different resistances. b) Corresponding $\operatorname{Im}(Z)$-part plotted against frequency.

The impact of fuel variations on the (V,I)-behavior is schematically illustrated in Fig. 2. The curve denoted as $\mathrm{fa}=\mathrm{n}$ represents the nominal fuel amount. fa $>\mathrm{n}$ and $\mathrm{fa}<\mathrm{n}$ represent an increase and a decrease with respect to the nominal fuel amount, respectively. As a result the maximum current density is shifting to the right and vice versa. Consequently the slopes of the cor- responding (V,I)-curves change as well. That implies that an increased fuel amount decreases the slope of the $(\mathrm{V}, \mathrm{I})$-curves and consequently the overall ASR $\left(\mathrm{ASR}_{\text {tot }}\right)$ that is defined by the local derivative $-\mathrm{d} V / \mathrm{d} j[8]$ and vice versa. Leakages might also influence the anodic fuel composition and the cathodic oxygen partial pressure by direct oxidation of fuel upstream to the cells. The impact of such leakages on (V,I)-curves is illustrated in Fig. 2 (labeled fm, fuel modification). Direct fuel oxidation upstream to the cell reduces the Nernst potential and thus the OCV. Since fuel oxidation reduces the overall fuel amount the maximum current is decreased too. Generally, a combination of these effects occurs in fuel cell stacks. For example, if the available fuel amount at the inlet of a single RU is higher than the nominal value and simultaneously the fuel composition is influenced by upstream leakages the maximum current density might just stay constant. However, in such a case the OCV is still decreased below its nominal value. This shows that for an accurate interpretation of experimental (V,I)-data both the OCV and the maximum current need to be taken into account. As fuel compositions affects the $\mathrm{ASR}_{\text {tot }}$, it is obvious that such variations lead to unfavorable scatter with respect to the overall repeat unit resistance. This further complicates the interpretation of (V,I)-data. Therefore concepts are needed to separate fuel gas effects $\left(\mathrm{ASR}_{\mathrm{gas}}\right)$ from the "true" internal $\mathrm{RU}$ resistance $\left(\mathrm{ASR}_{\mathrm{RU}}\right)$ in order to correctly interpret the $(\mathrm{V}, \mathrm{I})$-data and the total resistance $\left(\mathrm{ASR}_{\mathrm{tot}}\right)$.

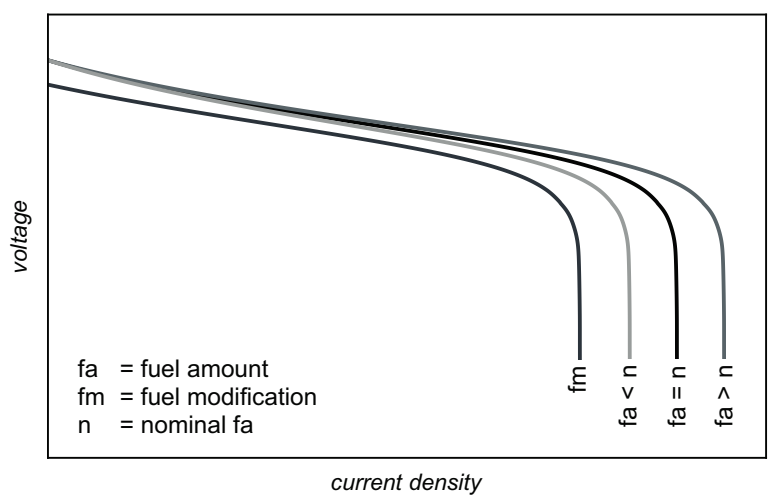

Figure 2: Schematic illustration of (V,I)-curves with typical influences of fuel amount variation (denoted as fa) and changes in fuel composition (denoted as fm).

\section{Model}

\subsection{Local equilibrium cascade model}

Fig. 1 shows the variation of EIS-spectra from a single cell within a stack upon changes in gas amount at 
$\approx 50 \%$ FU. The two main regions that can be correlated with $\mathrm{ASR}_{\mathrm{RU}}$ and $\mathrm{ASR}_{\text {gas }}$ are discussed separately below.

Fig. 1 shows that the $\mathrm{ASR}_{\mathrm{RU}}$ undergoes only very small changes compared to the total resistance $\mathrm{ASR}_{\text {tot }}$. This indicates that the $\mathrm{ASR}_{\mathrm{RU}}$ does not vary (e.g. as a model assumption) as a function of the available fuel amount and gas concentration, respectively. In principle, $\mathrm{ASR}_{\mathrm{RU}}$ varies with temperature since it depends on electrode polarization resistance, electrolyte and oxide scales conductivities, which have a temperature dependency themselves [20, 21, 30, 31]. However, for the Hexis stack design including metallic interconnects with high thermal conductivities in the range of 24$94 \mathrm{~W} \mathrm{~m}^{-1} \mathrm{~K}^{-1}[32,33]$ the heat transfer between the stack and the post combustion zones [12] is very efficient. Consequently the temperature is rather uniform and thus $\mathrm{ASR}_{\mathrm{RU}}$ is nearly constant over the entire cell/MIC (e.g. fuel inlet or adjacent to post combustion zone). A constant $\mathrm{ASR}_{\mathrm{RU}}$ also indicates the absence of gas transport limitations within the electrodes, which is typical for design with electrolyte supported cells. The polarization losses can thus be considered as linearly dependent on electrical current (ohmic law), which are not significantly affected by the local anodeand cathode gas compositions. Overall, the $\mathrm{ASR}_{\mathrm{RU}}$ becomes nearly independent from the load point i. e. fuel utilization. Furthermore, in a RU-model it is justified to assume uniform voltage distribution over the entire current-collector due to the high electrical conductivity in these components [32-35]. Hence an externally applied voltage $U_{\mathrm{L}}$ holds for the entire repeat unit.

Figs. 1 and 2 document that changes in fuel amount and composition basically affect the $\mathrm{ASR}_{\text {tot }}$ and not the $\mathrm{ASR}_{\mathrm{RU}}$. Due to the ongoing fuel utilization the gas composition varies within the cell and along gas channels, respectively. To capture the fuel consumption along a repeat unit more realistically, a spatial discretization of the RU by subdividing it into an arbitrary number of compartments that are connected to each other is made. Such a scenario is shown in Fig. 3a. Each compartment has a fuel gas composition that is assumed to be in thermodynamic equilibrium taking into account the water gas shift reaction. This is justified by the high operation temperatures and the catalytic active $\mathrm{Ni}$ present at anode side [36]. The local voltage of each compartment can then can calculated from the Nernst equation

$$
U_{\mathrm{N}}=\frac{k_{B} T}{4 e} \ln \left(\frac{p_{\mathrm{O}_{2}}^{\mathrm{C}}}{p_{\mathrm{O}_{2}}^{\mathrm{A}}}\right)
$$

for a given composition of anode and cathode gases within a single cascade element. In Eq. (2), $k_{B}$ is the
Bolzmann constant, $T$ the absolute temperature, $e$ the elementary charge and $p_{\mathrm{O}_{2}}$ the oxygen partial pressure on the cathode (C) and anode (A) side, respectively [37].

a

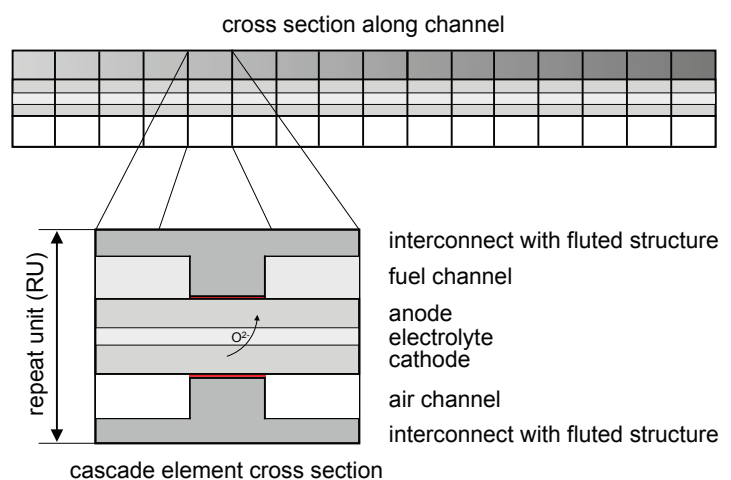

b

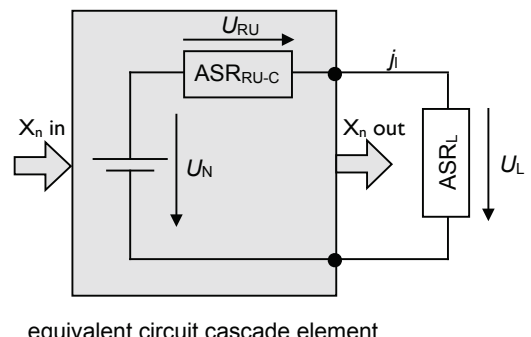

Figure 3: a) Schematic illustration of the model based on cascade elements along the flow channels of a SOFC stack repeat unit. The enlargement shows the cross section of the RU for a single cascade element. An electrical equivalent circuit for a single cascade element is shown in b). $X_{n}$ denotes the specific molar fractions for the fuel gas composition at the inlet and outlet, respectively.

The fuel composition in the first compartment at the anode inlet corresponds to the reformed natural gas in thermodynamic equilibrium at a given cell temperature and relevant pressure. In this work, the thermodynamic equilibrium is determined with the open-source software package Cantera [38]. Details about the natural gas composition are given by gas chromatography or from the local gas suppliers. Air is supplied to the cathode side. With the above made assumptions, the current-voltage behavior of each compartment can be represented by the equivalent circuit as shown in Fig. 3b. Since the externally applied voltage $U_{\mathrm{L}}$ is constant over the whole repeat unit the local repeat unit voltage drop is obtained as the difference between the local Nernst voltage and the external voltage, i. e.

$$
U_{\mathrm{RU}}=U_{\mathrm{N}}-U_{\mathrm{L}}
$$

The local current density $j_{1}$ then follows as the ratio of the repeat unit voltage and the assumed repeat unit re- 
sistance $\mathrm{ASR}_{\mathrm{RU}-\mathrm{C}}$ in the cascade model, i. e.

$$
j_{1}=\frac{U_{\mathrm{RU}}}{\mathrm{ASR}_{\mathrm{RU}-\mathrm{C}}} .
$$

The term $\mathrm{ASR}_{\mathrm{RU}-\mathrm{C}}$ is specifically used to denominate $\mathrm{ASR}_{\mathrm{RU}}$ values that are determined by the cascade model based on experimental (V,I)-data. Knowing the local current density the corresponding $\mathrm{O}^{2-}$ flux density $\dot{n}_{\mathrm{l}^{2-}}$ across the electrolyte can be calculated by Faraday's law

$$
\dot{n}_{\mathrm{O}^{2-}}=\frac{j_{1}}{2 F}
$$

whereas $F$ is the Faraday constant. A new gas composition originates from the $\mathrm{O}^{2-}$ transport across the electrolyte, which leads to a changed thermodynamic equilibrium state. This process also results in a new thermodynamic equilibrium for the water-gas shift reaction and the steam reforming of the remaining hydro-carbonates (e. g. $\mathrm{CH}_{4}, \mathrm{C}_{2} \mathrm{H}_{6}, \mathrm{C}_{3} \mathrm{H}_{8}$ ) [11]. The resulting gas concentrations are used to determine $U_{\mathrm{N}}$ in the following downstream element based on Eq. (2). The $\mathrm{O}_{2}$ consumption on the cathode side known from Eq. (5) is likewise considered in the calculation. This procedure is sequentially repeated from inlet to outlet for all $n$ cascade elements. Finally, the averaged cell currentdensity $j$ is obtained as the sum over all local currentdensities dived by the number of cascade elements $n$

$$
j=\frac{\sum_{i=1}^{n} j_{1_{i}}}{n}
$$

The modeled (V,I)-characteristic is finally obtained from the given load $U_{\mathrm{L}}$ and the resulting global current density $j$ at each load point.

Since $\mathrm{ASR}_{\mathrm{RU}-\mathrm{C}}$ is initially unknown, it is obtained from fitting the model to $(\mathrm{V}, \mathrm{I})$-data. This is here done using the method of least squares to minimize the error between the cascade model and the experimental data.

The cascade model takes the real fuel composition and fuel amount at the inlet as input. However, because of fuel leakages and changes in the natural gas composition when provided from the grid both are generally unknown but can be assessed by comparing the nominal values for the OCV and maximum current with the real ones obtained from $(\mathrm{V}, \mathrm{I})$-data.

\subsection{Accounting for fuel leakages and compositional variations}

Fuel leakages reduce the total amount of available fuel or alter the fuel composition. These gas effects may lead to a reduction of the OCV, see Eq. (2). Uneven fuel distribution between the different repeat units within a stack affects the fuel amount available for a certain RU. The influences on (V,I)-data by fuel leakages and uneven fuel distribution are illustrated in Fig. 4. This Figure also includes two sets of data which exhibit the same OCV but different maximum currents and therefore different total resistances $\mathrm{ASR}_{\mathrm{tot}}$. Their OCV is reduced, when compared with the nominal (V,I)-characteristic shown as the black curve. This indicates the presence of leakages that alter the fuel composition at the inlet with respect to the nominal inlet composition. This kind of leakage is usually related to leaking air upstream to the cell that necessarily leads to a partial oxidation of fuel. In the model such partial oxidation leads to a new nominal $(\mathrm{V}, \mathrm{I})$-characteristic with a reduced OCV that corresponds to the experimental OCV. Further details are given in our previous work [11]. The resulting $(\mathrm{V}, \mathrm{I})$-curve is illustrated by the gray line in Fig. 4. This modeled curves still differs from the experimental data sets with respect to their maximum currents $j_{\max }$. Set 1 exhibits a higher $j_{\max }$-value than the model and set 2 a smaller one. This means (V,I)-data represented by set 1 gets a higher than nominal net fuel amount and vice versa for data represented by set 2 . Hence the modeled (V,I)-curve (gray curve) needs to be adjusted with respect to the fuel amount available at the cell inlet by matching the $j$-values of the provided experimental data. The available amount of fuel is determined from present $j$-values at the characteristic bend at high FUs. It must be emphasized that in our experiments the fuel utilization is generally limited to $95 \%$ in order to avoid Ni-oxidation [39]. This limits the range of experimental (V,I)-data.

The voltage drop at fuel utilizations close to $100 \%$ is more pronounced in the derivative $-\mathrm{d} V / \mathrm{d} j$ of $(\mathrm{V}, \mathrm{I})$-data (see e.g. Fig. 6). Building a simple difference quotient based on the experimental data is often insufficient due to the unavoidable signal noise during the measurement. Therefore a logistic growth function

$$
\operatorname{ASR}_{\mathrm{RU}-\mathrm{C}} j=-M+\frac{\ln \left(\frac{j-B}{\mathrm{C}-j}\right)}{G}, C \leq j \leq B
$$

with four degrees of freedom is used to describe the experimental data where $C=j$ represents the asymptotic limit at the left side, $B=j$ the increment between the left and right side asymptotes and $G$ the gradient at the inflection position $M=j$. To improve the fit quality an additional symmetry factor $S$ is included

$$
\operatorname{ASR}_{\mathrm{RU}-\mathrm{C}} j=M-\frac{\ln \left(\frac{\left(\frac{B-C}{B-j}\right)^{S}-1}{S}\right)}{G}, C \leq j \leq B .
$$




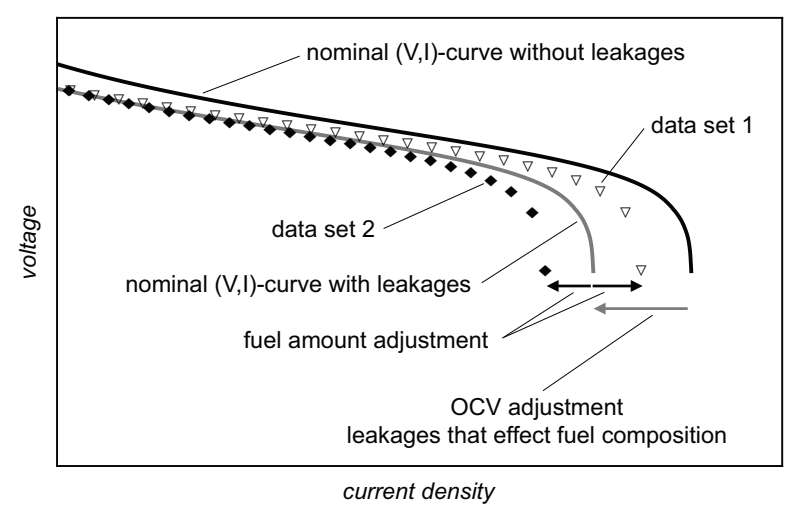

Figure 4: Illustration of the influence of fuel leakages for two types of (V,I)-data. The black curve represents the nominal (V,I)-curve. The gray curve represents the modeled (V,I)-curve including only fuel leakage effects i. e. without any additional fuel amount deviation. The symbols schematically illustrate two different types of experimental data, which include fuel leakages that affect the fuel composition upstream to the cell. The triangles illustrate experimental data with a fuel oversupply and the diamonds with a fuel under supply, respectively.

whereby the resulting parameters from the experimental data description by Eq. (7) are required to find reasonable parameters for Eq. (8) with five degrees of freedom. An example of fitted experimental data with both function is shown in Fig. 5.

The experimental (V,I)-data and the modeled (V,I)-data are described by the functions given in Eq. (7) and Eq. (8), respectively, to determine the effectively available fuel amount on each RU. The fuel amount fitting is an iterative procedure based on least square where the derivative of the modeled $(\mathrm{V}, \mathrm{I})$-characteristic is fitted to the derivative of the experimental (V,I)-data. Fig. 6 illustrates the derivatives of the modeled (V,I)-characteristics for the nominal $(100 \%)$ and the adjusted fuel. Thereby the latter one shows a good agreement with the experimental data. To find a robust solution only a defined section between the maximum in the derivative of experimental (V,I)-data and a predefined value at high current densities is used during this fitting procedure.

\subsection{Model process}

To evaluate the internal resistance and the effective fuel amount for a single cell the different subroutines as described above are combined in a global routine. The overall procedure is illustrated in the flowchart in Fig. 7. This procedure can be repeated at different time steps to extract a time-depend $\mathrm{ASR}_{\mathrm{RU}-\mathrm{C}}$ to study RU degradation based on (V,I)-data.

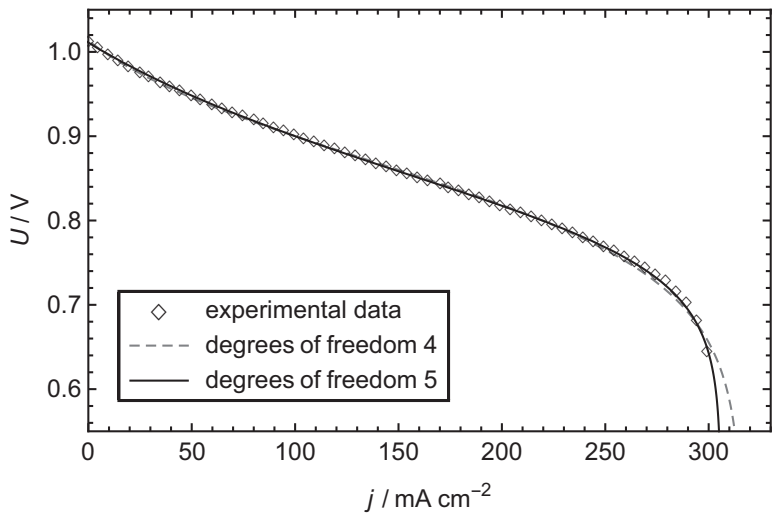

Figure 5: Experimental IV-data after $200 \mathrm{~h}$ stack operation at $900^{\circ} \mathrm{C}$ with CPOx reformed natural gas, described by the fit functions with four and five degrees of freedom, Eqs. (7) and (8), respectively.

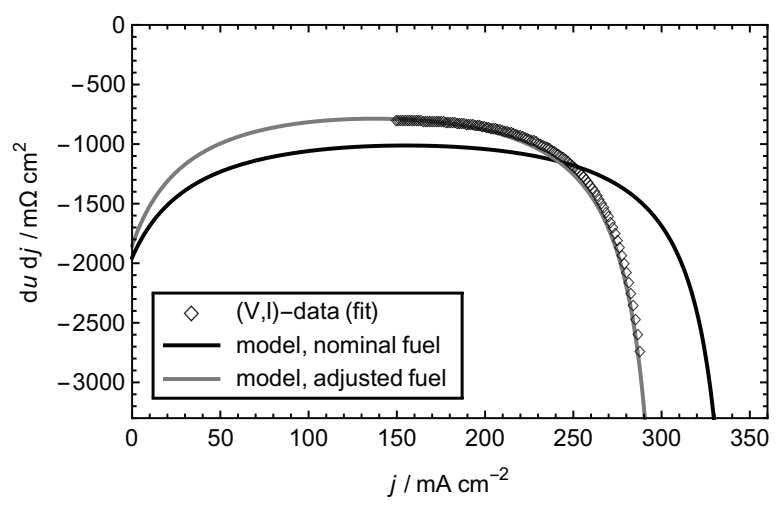

Figure 6: Schematic illustration of the fuel fit. The black data points represents the derivative of the fitted experimental data and the curves represent the derivative of the modeled (V,I)-data for different fuel amounts. The black curve represent the derivative of modeled (V,I)-curve for the nominal fuel amount $(100 \%)$ and the gray curve for a fitted fuel amount $(<100 \%)$, respectively.

\subsection{Degradation model}

A degradation model is introduced, which describes time dependent behavior of single $\mathrm{ASR}_{\mathrm{RU}}$ components: $\operatorname{ASR}_{\text {MIC }}(t)$ including the ohmic resistance of the growing $\mathrm{Cr}_{2} \mathrm{O}_{3}$ scale on the metallic interconnect, $\operatorname{ASR}_{\text {con }}(t)$ the contact resistance, $\mathrm{ASR}_{\mathrm{el}}(t)$ the electrolyte resistance and $\operatorname{ASR}_{\mathrm{an}}(t)$ as well as $\operatorname{ASR}_{\mathrm{cn}}(t)$ the electrode resistances. If available, the time dependent degradation behavior for the individual terms are derived from single experiments e.g. conductivity measurements under cathode conditions [40]. Otherwise they are extracted from averaged long term stack measurements. The sum of these different RU resistances

$$
\begin{aligned}
\operatorname{ASR}_{\mathrm{RU}-\Sigma}(t) & =\operatorname{ASR}_{\mathrm{MIC}}(t)+\operatorname{ASR}_{\mathrm{con}}(t)+\operatorname{ASR}_{\mathrm{el}}(t) \\
& +\operatorname{ASR}_{\mathrm{an}}(t)+\operatorname{ASR}_{\mathrm{ca}}(t)
\end{aligned}
$$




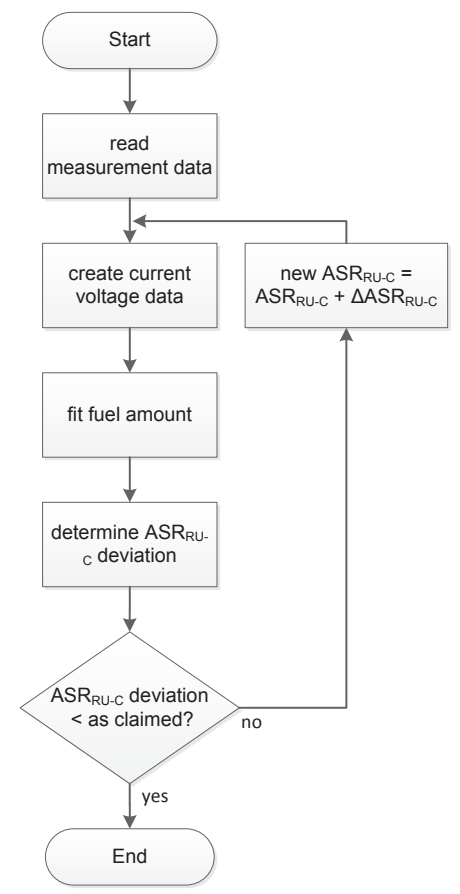

Figure 7: Illustration of the overall cascade model procedure to determine $\mathrm{ASR}_{\mathrm{RU}-\mathrm{C}}$ based on experimental (V,I)-data.

can be compared with $\mathrm{ASR}_{\mathrm{RU}-\mathrm{C}}$ determined from experimental data with the cascade model. If the difference between $\operatorname{ASR}_{\mathrm{RU}-\Sigma}(t)$ and $\mathrm{ASR}_{\mathrm{RU}-\mathrm{C}}$ turns to zero it can be concluded that the stack behaves as expected based on the degradation model.

\section{Experiments for model validation}

The experimental work is done with electrolyte supported SOFCs in the planar Hexis design arranged in an open stack with a direct post combustion. These experiments are realized in short stacks consisting of five standard cells with an active cell area of $100 \mathrm{~cm}^{2}$. The stacks are running with catalytic partial oxidized (CPOx) natural gas from the local grid. The nominal gas flux for one $\mathrm{RU}$ is defined as $4 \mathrm{~g} \mathrm{~h}^{-1}(\approx 50 \mathrm{~W})$. The stack temperature is set between 850 and $900^{\circ} \mathrm{C}$.

\section{1. (V,I)-characteristics}

The drawing for the (V,I)-characteristics starts at OCV. Thereafter the current from the external load is stepwise $(0.5 \mathrm{~A})$ increased. At each point a dwell of $120 \mathrm{~s}$ is predefined to ensure steady state conditions before logging the resulting cell potential. This procedure is repeated until the abort criterion $<0.6 \mathrm{~V}$ is reached for one cell in the five cell stack. Gas fluxes and temperatures are constant during the (V,I)-measurement. $(\mathrm{V}, \mathrm{I})$-characteristics are measured for each single cell within the 5-cell stack.

\subsection{EIS measurement}

EIS measurement is realized with a Zahner IM6(ex) in combination with Zahner PP240 potentiostat. The measurements are done with an external load at $15 \mathrm{~A}$ $\left(150 \mathrm{~mA} \mathrm{~cm}^{-2}\right)$, which corresponds approximately to $50 \% \mathrm{FU}$ with an amplitude of $1 \mathrm{~A}$. The frequency domain is defined between $50 \mathrm{kHz}$ and $20 \mathrm{mHz}$. Deviations from this standard measurement parameters are explicitly mentioned in this work.

\subsection{Gas chromatography}

The natural gas composition from the local grid in Winterthur (Switzerland) is analyzed half-hourly to ensure that the relevant gas data for the model based analysis are available. The gas composition is determined with an Agilent Varian CP-4900 gas chromatograph.

\section{Results and Discussion}

In this section a detailed model validation focusing on the accuracy of determined $\mathrm{ASR}_{\mathrm{RU}-\mathrm{C}}$ data and fuel amounts is presented at the beginning. Then comparison of results from experiments and from degradation models for the single stack components and their potential to detect deviations from the averaged stack behavior will be discussed. The possibility to extract local RU conditions that are relevant for further degradation studies is introduced as an additional cascade model feature at the end of this section.

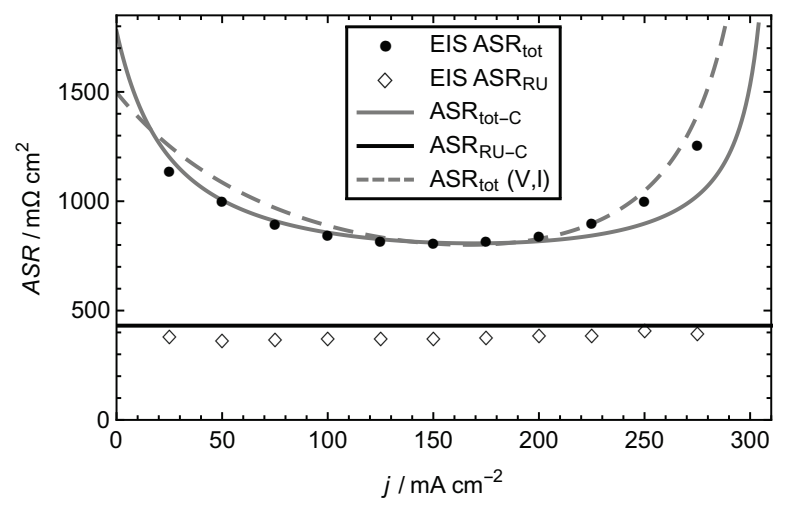

Figure 8: Comparison of ASR values extracted from EIS measurements with experimental and modeled (V,I)-data respectively. The cell was operated at $850^{\circ} \mathrm{C}$ with CPOx reformed natural gas at corresponding load points. 


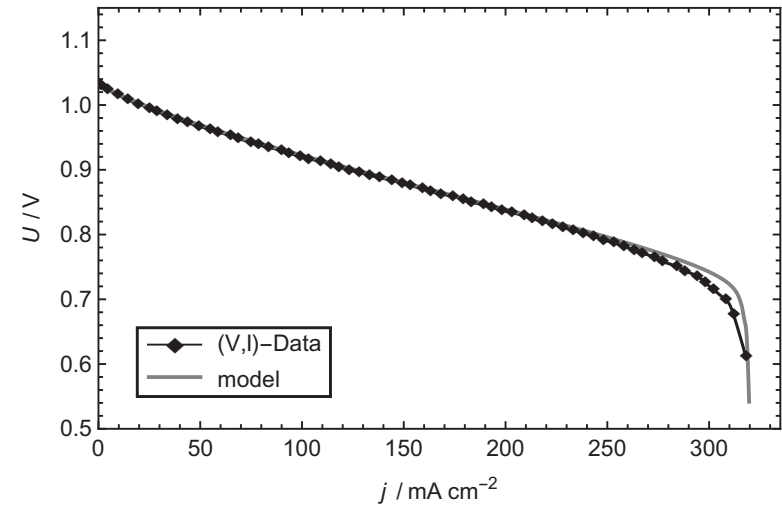

Figure 9: Comparison between experimental (V,I)-data $\left(850^{\circ} \mathrm{C}\right.$, CPOx reformed natural gas) with (V,I)-data from cascade model fit. The cascade model considers leakages and fuel amount deviations.

\subsection{Model validation}

The hypothesis that $\mathrm{ASR}_{\mathrm{RU}}$ is independent of the fuel amount is validated by the EIS-data shown in Fig. 1a for a single cell. This Figure shows that no significant changes in the polarization arcs can be observed even for an extraordinary large fuel amount variation between 2 and $6 \mathrm{~g} \mathrm{~h}^{-1}$.

To further validate the cascade model, its $(\mathrm{V}, \mathrm{I})$-behavior is compared with experimental (V,I)-data from one cell obtained from a Hexis 5-cell stack operated at $850^{\circ} \mathrm{C}$ and fueled with $\mathrm{CPOx}$ reformed natural gas. Fig. 8 shows $\mathrm{ASR}_{\text {tot }}$ and $\mathrm{ASR}_{\mathrm{RU}}$ data plotted against current density extracted from EIS, experimental and modeled (V,I)-data, respectively. $\mathrm{ASR}_{\mathrm{RU}}$ extracted from the EIS-data are illustrated by the diamonds for the different current densities. The scatter of these data is small and shows a horizontal

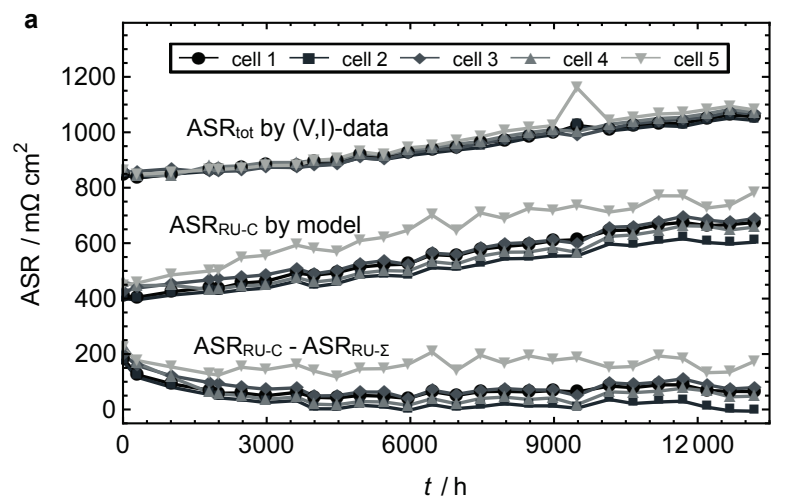

behavior, which confirms that $\mathrm{ASR}_{\mathrm{RU}}$ can be considered as being constant and can therefore be modeled independently from load variations in the cascade model. The dots illustrate the $\mathrm{ASR}_{\text {tot }}$ as provided by the EIS data. The dashed curve show the $\mathrm{ASR}_{\text {tot }}$ trend based on the derivative $-\mathrm{d} V / \mathrm{d} j$ of measured (V,I)-data. $\mathrm{ASR}_{\mathrm{RU}-\mathrm{C}}$ is represented by the black line at $432 \mathrm{~m} \Omega \mathrm{cm}^{2}$, which show a good agreement with the relevant EIS data. $\mathrm{ASR}_{\text {tot-C }}$ behavior resulting from the cascade model is shown by the gray curve. Fig. 8 illustrates that the cascade model agrees well with the data for current-densities up to $250 \mathrm{~mA} \mathrm{~cm}^{-2}$. However, for higher current-densities the agreement becomes rather poor. Apparently, this mismatch does not affect the ability of the cascade model to accurately predict $\mathrm{ASR}_{\mathrm{RU}-\mathrm{C}}$. Experimental $(\mathrm{V}, \mathrm{I})$-data from the same cell are shown in Fig. 9 by the symbols. The gray curve represents the (V,I)-curve as fitted by the cascade model. This curve is only visible for current densities $>250 \mathrm{~mA} \mathrm{~cm}^{-2}$ due to the good agreement with the experimental data.

ASR trends extracted from the (V,I)-data and EIS measurements are compared in Fig. 10 to verify consistency. The data at the top in Fig. 10a show the $\mathrm{ASR}_{\text {tot-C }}$ evolution during stack operation for a five cell stack operated at $850^{\circ} \mathrm{C}$ with $\mathrm{CPOx}$ reformed natural gas extracted from $(\mathrm{V}, \mathrm{I})$-data. The $\mathrm{ASR}_{\mathrm{RU}-\mathrm{C}}$ trends are shown in the middle. Fig. $10 \mathrm{~b}$ show as well $\mathrm{ASR}_{\text {tot }}$ and $\mathrm{ASR}_{\mathrm{RU}}$ trends from the same stack derived from EIS measurement. In general the (V,I)- and EIS-data agree well with each other, which confirms the reliability and accuracy of the cascade model. Except for repeat unit number 5 in Fig. 10a where ASR $\mathrm{RU}_{\mathrm{C}}$ is clearly higher compared to the corresponding trend extracted from EIS. This be-

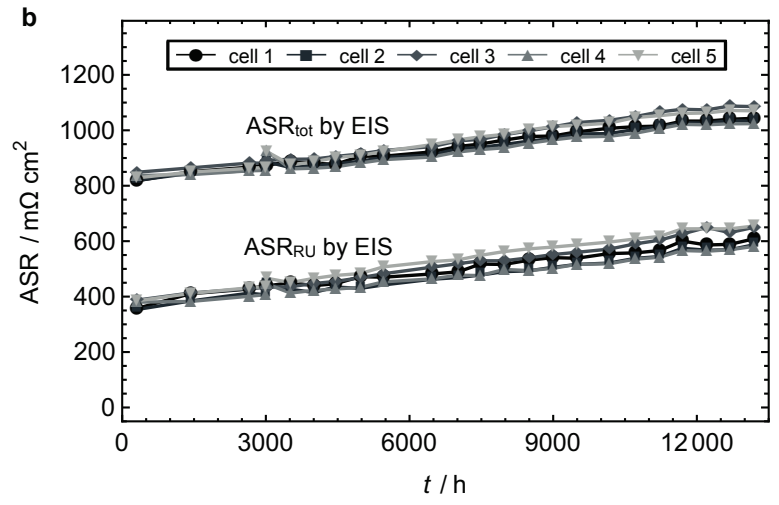

Figure 10: a) Degradation behavior extracted from (V,I)-data of a Hexis 5-cell stack operated at $900^{\circ} \mathrm{C}$ with $\mathrm{CPOx}$ reformed natural gas. The top family of curves represents the total ASR increase for each cell. The middle ones represent the increase of ASR $\mathrm{RU}_{\mathrm{C}}$ determined by the cascade model. The curves at the bottom represent the difference between $\mathrm{ASR}_{\mathrm{RU}}$ from the cascade model and from the degradation model (cf. section 3.4). b) $\mathrm{ASR}_{\text {tot }}$ and $\mathrm{ASR}_{\mathrm{RU}}$ trends extracted from EIS measurements 
havior is related to a none uniform fuel distribution within the stack where cell number 5 is oversupplied. This instability lead to a reduction of gas concentration losses and consequently of $\mathrm{ASR}_{\text {tot }}$. In this specific case $\mathrm{ASR}_{\mathrm{RU}-\mathrm{C}}$ is additionally overestimated by the cascade model, which is using the characteristic bend at high FU to determine the effective available fuel amount (cf. Fig. 6). This feature in (V,I)-data is missing here, hence the effective fuel amount is overestimated. Nevertheless, the cascade model provides a reliable indication that repeat unit 5 is oversupplied as confirmed by the corresponding Nyquist plots and by the $\mathrm{ASR}_{\mathrm{RU}}$ trend in Fig. 10b. Furthermore it could be shown for other examples that a performance rating for single cells based on (V,I)-data can lead to a misinterpretation. This is due to non-uniform fuel supply within SOFC stacks, which can have a strong influence on each repeat unit and consequently on the corresponding effective operating behavior.

The capability of the cascade model to predict the true fuel amount feed to a specific repeat unit is documented in the following section. As shown in Fig. 11, the gas concentration impedance extracted from the spectra shown in Fig. 1 follows a linear correlation with the inverse of the corresponding fuel amount. Furthermore the regression line has only a marginal offset from the origin. Hence, the experimental data show a good agreement with the theoretical behavior, where the gas concentration resistance must be zero for an infinite fuel amount $[26,28,41]$. This relation is used to determine the fuel distribution over the various repeat units of a Hexis 5-cell stack based on EIS data. A detailed comparison between fuel deviation based on EIS data and extracted by the cascade model is shown in Fig. 12 for two cases. In one case (Fig. 12c) the deviation is below $3 \%$. In another case (Fig. 12d) the fuel amounts deviate from the nominal value by up to $10 \%$. Both fuel amounts determined by the cascade model are confirmed by changes of the gas concentration impedance data as shown in Fig. 12a, 12b and in the corresponding bars in $12 \mathrm{c}$ and $12 \mathrm{~d}$, respectively. However, the deviation between these two stacks is not related to a faulty design, but rather to production tolerances, assembling issues or leakages. Note, the high frequency intercept that corresponds to the ohmic resistance in the Nyquist plots (Fig. 12a and 12b) are shifted for each cell to the same point. The aim of this adjustment is to illustrate more clearly the variation in the size of the gas concentration arcs in the low frequency region, which are affected by the available fuel amount.

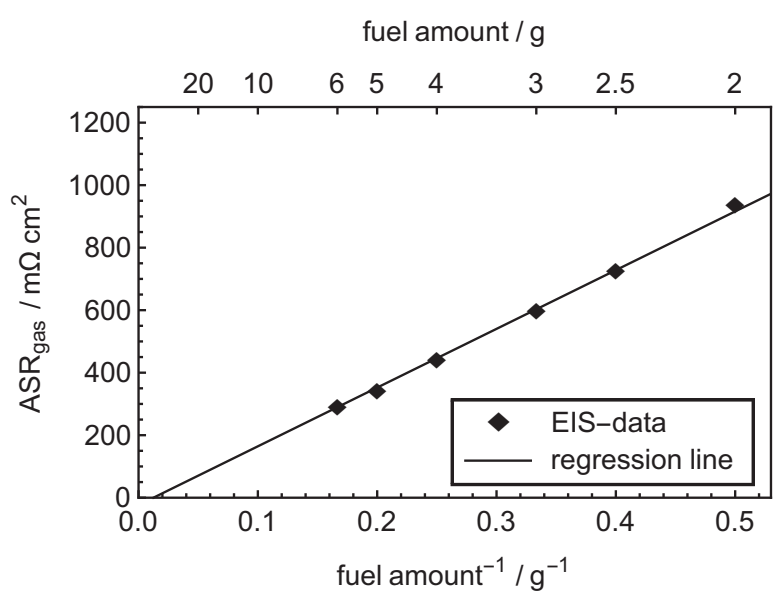

Figure 11: $\mathrm{ASR}_{\text {gas }}$ extracted from EIS-data, as a function of the inverse fuel amount. All data points are measured at $50 \% \mathrm{FU}$.

\subsection{Comparison of experimental data with degrada- tion model}

The cascade and degradation models enable the comparison between internal resistances under stack operation $\left(\mathrm{ASR}_{\mathrm{RU}-\mathrm{C}}\right)$ and the sum of the resistances of individual stack components $\left(\operatorname{ASR}_{\mathrm{RU}-\Sigma}(t)\right)$ obtained either from single laboratory experiments or from averaged experimental stack analysis (cf. section 3.4). If all local degradation phenomena within a stack can be described by $\operatorname{ASR}_{\mathrm{RU}-\Sigma}(t)$ then the difference to the extracted $\mathrm{ASR}_{\mathrm{RU}-\mathrm{C}}$ should consequently turn to zero. The ASR trends at the bottom of Figs. 10a represent the residual by subtracting $\operatorname{ASR}_{\mathrm{RU}-\Sigma}(t)$ based on single degradation effects (degradation model), from the repeat unit resistance $\mathrm{ASR}_{\mathrm{RU}-\mathrm{C}}$ calculated by cascade model based on experimental (V,I)-data. The widely horizontal ASR trends around zero features that the applied degradation models includes all relevant degradation losses. The above discussed overestimation of $\mathrm{ASR}_{\mathrm{RU}-\mathrm{C}}$ in Fig. 10a for cell number 5 is consequently still present since $\operatorname{ASR}_{\mathrm{RU}-\Sigma}(t)$ does not implicitly include a fuel amount misinterpretation. However, within the first $3000 \mathrm{~h}$ some phenomenas take place that are not taken into account properly by $\operatorname{ASR}_{\mathrm{RU}-\Sigma}(t)$. This can be associated with reverse effects between contact resistance, by settling phenomena, coating and interfering oxide formation effects on the MIC within this initial period influencing the electrical conductivity [42-51].

Fig. 13 shows the ASR evolutions for another stack that was operated at $900^{\circ} \mathrm{C}$ with CPOx reformed natural gas. The residual curves at the bottom line $\left(\mathrm{ASR}_{\mathrm{RU}-\mathrm{C}}\right.$ - $\left.\operatorname{ASR}_{\mathrm{RU}-\Sigma}(t)\right)$ show also the decreasing trend within the first $3000 \mathrm{~h}$ that turns into the expected horizontal 

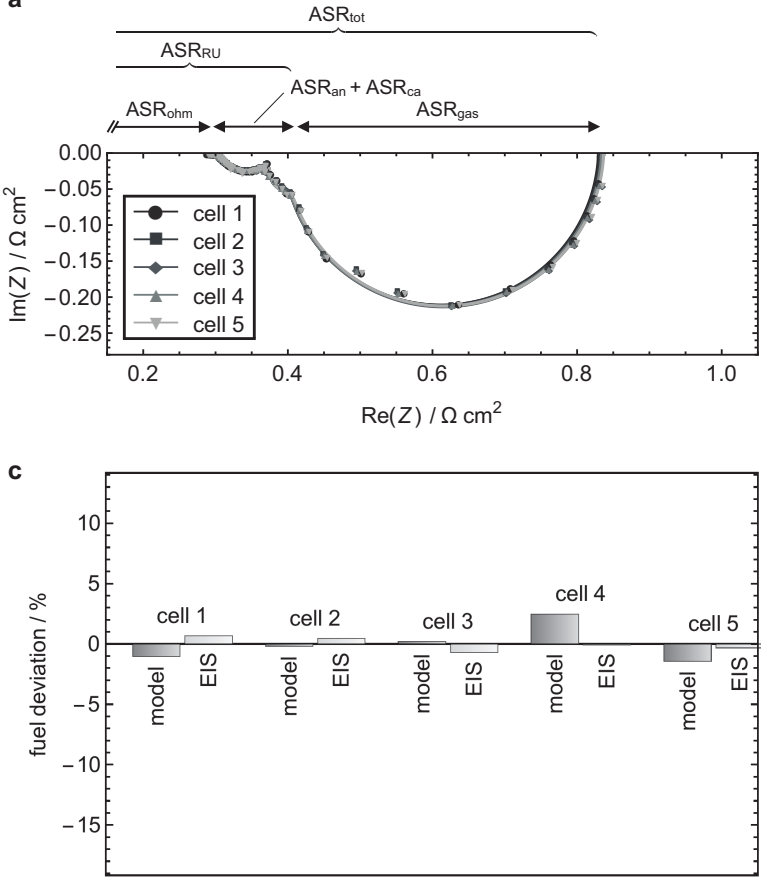
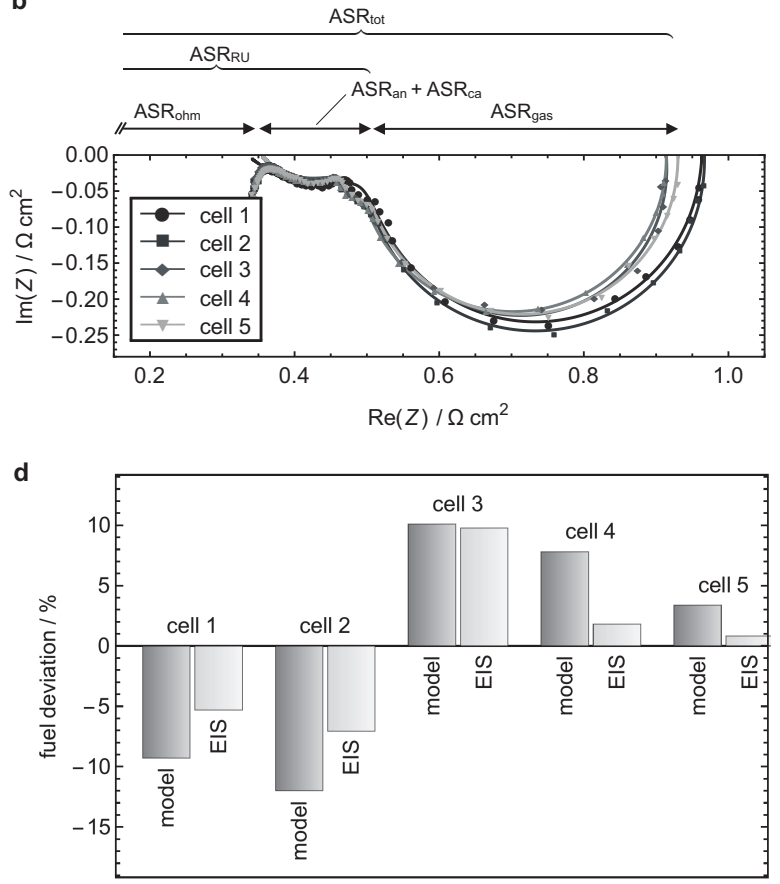

Figure 12: a) EIS spectra with small fuel variation extracted from a five cell short stack operated at $850{ }^{\circ} \mathrm{C}$ with $\mathrm{CPOx}$ reformed natural gas after 1120 h. b) EIS spectra measured in a five cell short stack at $900^{\circ} \mathrm{C}$ after $9600 \mathrm{~h}$ stack operation with CPOx reformed natural gas. c) Standardized fuel deviation determined by the cascade model compared to the corresponding EIS data shown in a). d) Standardized fuel deviation determined by the cascade model and by EIS for b). Fuel feed irregularities indicated either by EIS or by the cascade model reproduce the trend with a good agreement.

behavior close to zero. After $8000 \mathrm{~h}$ the ASR curves show an irregular and pronounced decrease. This irregularity is related to a thermocouple drift. Thermodynamic calculations show that the temperature increase must be in the range of $100^{\circ} \mathrm{C}$, since the $\mathrm{OCV}$ was reduced by $30 \mathrm{mV}$ within $1000 \mathrm{~h}$. After the thermocouple replacement at $t \approx 9000 \mathrm{~h}$ the residual trends at the bottom line show a clearly recognizable increase which is not captured by the applied degradation model $\operatorname{ASR}_{\mathrm{RU}-\Sigma}(t)$. We believe that the stack temperature excursion to around $1000^{\circ} \mathrm{C}$ has induced an excessive and irreversible degradation. This example illustrates that model based analysis of IV-data in combination with a degradation model $\left(\mathrm{ASR}_{\mathrm{RU}-\Sigma}(t)\right)$ can help to identify unexpected degradation phenomena. Such a identification can be applied in real time. Thus, some corrective action for the stack operation can be taken immediately.

\subsection{Further model features}

For the entire series of connected elements, the cascade model enables to extract information about local species concentration, current density and Nernst potential. The graphs in Fig. 14 on the left side (14a,
$14 \mathrm{c}, 14 \mathrm{e})$ represent the local current density $j_{1}$ and the Nernst potential $U_{\mathrm{N}}$, respectively as function of cell radius $r$ at different FUs. The curves for the local Nernst potential have a constant slope at low FU, but show changes in slope at high FU. The local Nernst potential starts independently of the load point (FU) at the OCV. This behavior is expected since at the channel inlet $(r=2 \mathrm{~cm})$ the gas composition is not altered by any fuel consumption. Regardless of the effective fuel utilization the Nernst potential $U_{\mathrm{N}}$ is decreasing along the fuel channels towards external load potential $U_{\mathrm{L}}$ at the channel outlet $(r=6 \mathrm{~cm})$. This behavior is related to the ohmic law and it is characteristic for the applied equivalent circuit in the cascade model, as shown in Fig. 3. The local current density $j_{1}$ also shows a decreasing behavior along the fuel channel, which correlates to the local Nernst potential. This is expected since, according to the ohmic law, the local current density must be proportional to $U_{1}$ for a constant $\mathrm{ASR}_{\mathrm{RU}}$ as provided by the cascade model.

Figs. 14b, 14d and 14f on the right side show the local molar fractions for the anode gas at different FUs along the fuel channels. These molar fractions result 

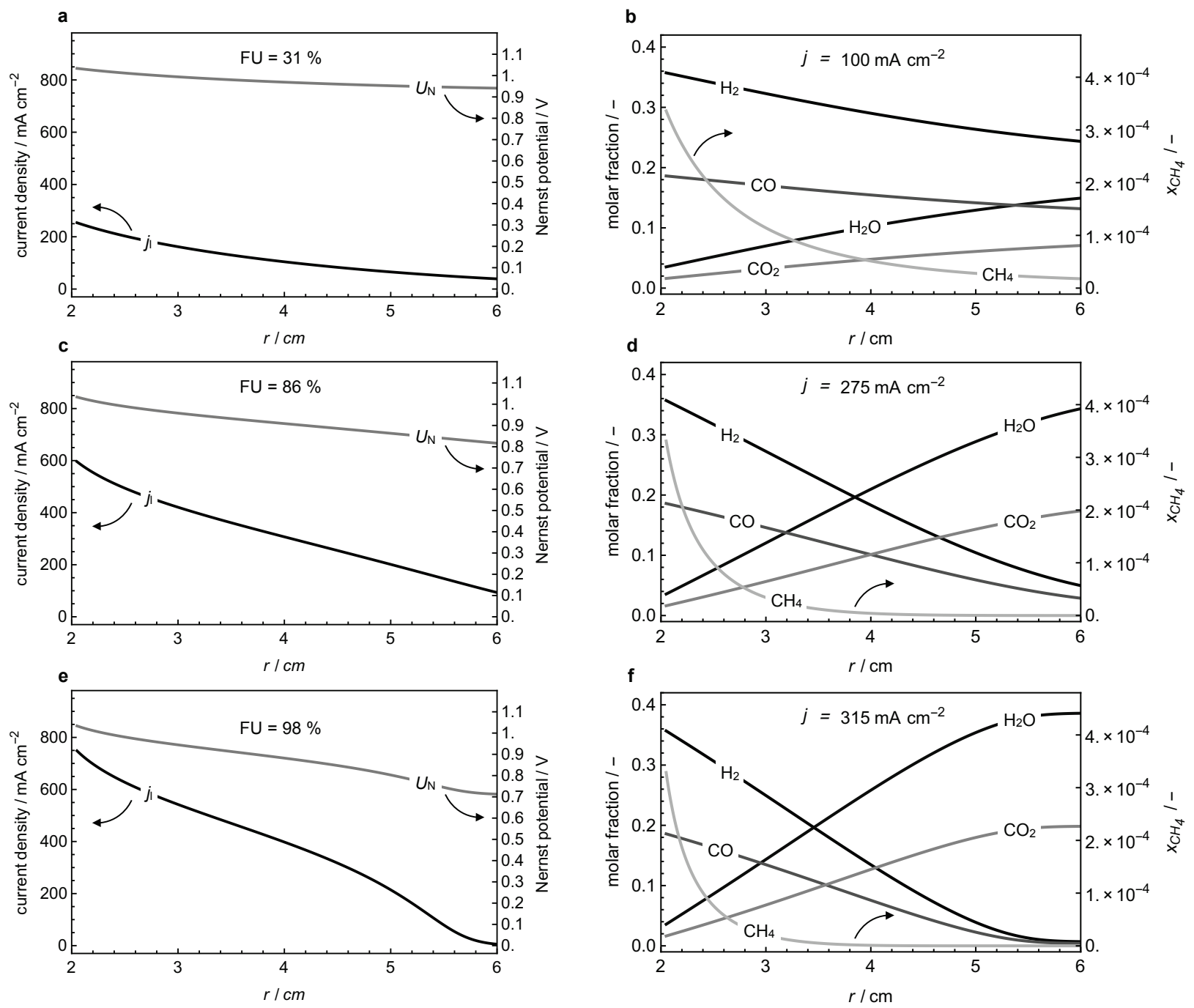

Figure 14: Graphs a), c) and e) represent the local current $\left(j_{1}\right)$ and Nernst potential $\left(U_{\mathrm{N}}\right)$, respectively as function of cell radius $(r)$ for different FUs with CPOx reformed natural gas at $850^{\circ} \mathrm{C}$. The local gas concentrations at the corresponding FUs are illustrated in b), d) and f).

from the thermodynamic equilibrium calculation based on the $\mathrm{O}^{2-}$ transport across the electrolyte (cf. Eq. 5). The inlet fuel mixture is identical for all fuel utilizations, which is consistent to the Nernst potential at the channel inlet (cf. Figs. 14a, 14c and 14e). The concentration of reagents $\left(\mathrm{CH}_{4}, \mathrm{H}_{2}\right.$ and $\left.\mathrm{CO}\right)$ decreases gradually along the channel. This decrease is obviously more pronounced at higher FU (cf. Figs $14 \mathrm{~d}$ and 14f). The products $\left(\mathrm{H}_{2} \mathrm{O}, \mathrm{CO}_{2}\right)$ correlate to the fuel oxidation and hence increase along the flow channel.

Transport limitation by diffusion along and orthogonal to the gas channels are neglected in the introduced cascade model. Nonetheless comparisons of the results from the cascade model (cf. Fig. 14) with data available in literature based on different model types show a good qualitative agreement [52-55].

The option to extract information about the local conditions that vary with FU as illustrated in Fig. 14 provides useful references to study the degradation behavior of different components under accurate conditions [49, 56-58].

\section{Conclusions}

The introduced cascade model takes into account stack effects like leakages and nonuniform fuel distribution that are often related to manufacturing tolerances and varieties in the natural gas composition. Consider- 


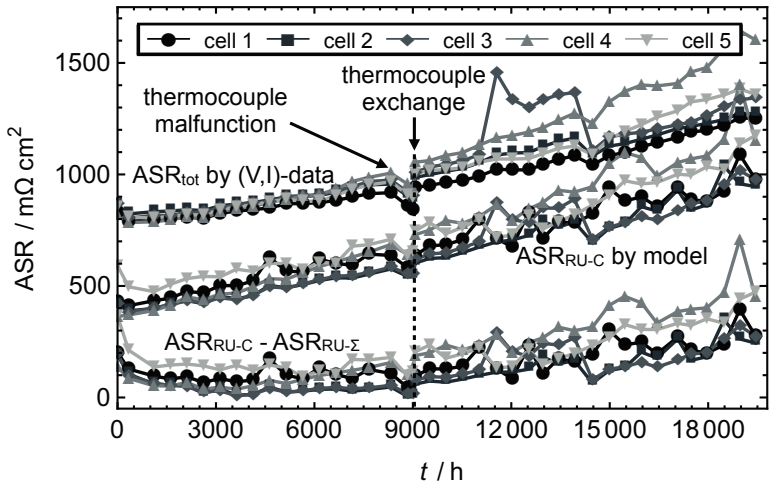

Figure 13: ASR trends from a five cell stack operated with CPOx reformed natural gas at $900^{\circ} \mathrm{C}$. Irregularities at ca. $9000 \mathrm{~h}$ represent an enhanced degradation due to instable temperature control. The top family of curves represents the $\mathrm{ASR}_{\text {tot }}$ increase for each cell. The middle set of the curves represent the increase of the $\mathrm{ASR}_{\mathrm{RU}-\mathrm{C}}$ determined by the cascade model. The curves at the bottom represent the remaining deviation between $\mathrm{ASR}_{\mathrm{RU}-\mathrm{C}}$ from cascade model and $\mathrm{ASR}_{\mathrm{RU}-\Sigma}$ from degradation model. (cf. section 3.4).

ing these effects is relevant for further stack improvement since degradation characterization based on an overall ASR trend can lead to misinterpretation.

Stack characterization with EIS is doubtless the favored method since the available information in impedance spectra can be separated into single loss constituents. However the required infrastructure for EIS analysis is expensive and not everywhere available e. g. for stacks running in the field. The introduced cascade model is able to quantify $\mathrm{ASR}_{\mathrm{RU}-\mathrm{C}}$ based on experimental (V,I)-data accurately. This is confirmed by comparison of $\mathrm{ASR}_{\mathrm{RU}-\mathrm{C}}$ trends extracted by the cascade model with those from EIS data. Hence the introduced model has the potential to provide additional information from SOFC stacks running in the field.

Comparing stack repeat unit degradation systematically with averaged degradation behaviors of the single contributions can also help to detect unusual stack behavior (especially during early stages of the operation). Based on these results the operating conditions can be adapted in a purposeful manner, in order to reduce degradation and finally to appropriate corresponding operation measures. Furthermore, the cascade model also provides the opportunity to extract local species concentrations within the stack and how these concentrations vary with FU. This is an important aspect that helps to understand cell performance and degradation. It contributes significantly to future improvements of the stack/cell design.

\section{Acknowledgment}

The authors wish to thank Roman Kruschwitz and Ueli Weissen for their unconditional support. We also would like to thank Swisselectric Research and the Swiss Federal Office of Energy for their financial support within the Swiss SOF-CH ESC project.

\section{References}

[1] A. Weber, E. Ivers-Tiffée, J. Power Sources 127 (2004) 273283.

[2] R. Steinberger-Wilckens, Proc. 12th Int. Symp. Solid Oxide Fuel Cells XII 35 (2011) 19-29.

[3] K. Föger, Proc. 10th Eur. SOFC Forum A0503 (2012) A0518A0524.

[4] A. Mai, B. Iwanschitz, R. Denzler, U. Weissen, D. Haberstock, V. Nerlich, A. Schuler, Proc. 10th Eur. SOFC Forum A0403 (2012) A0420-A0427.

[5] A. Nanjou, Proc. 10th Eur. SOFC Forum A0202 (2012) A028.

[6] R. R. Mosbæ k, J. Hjelm, R. Barfod, J. Hø gh, P. V. Hendriksen, Fuel Cells 13 (2013) 605-611.

[7] S. P. Simner, M. D. Anderson, G. Xia, Z. Yang, L. R. Pederson, J. W. Stevenson, J. Electrochem. Soc 152 (2005) 740-745.

[8] R. S. Gemmen, M. C. Williams, K. Gerdes, J. Power Sources 184 (2008) 251-259.

[9] L. G. J. de Haart, J. Mougin, O. Posdziech, J. Kiviaho, N. H. Menzler, Fuel Cells 9 (2009) 794-804.

[10] J. Malzbender, R. W. Steinbrech, L. Singheiser, Fuel Cells 9 (2009) 785-793.

[11] M. Linder, T. Hocker, R. Denzler, A. Mai, B. Iwanschitz, Fuel Cells 11 (2011) 573-580.

[12] A. Mai, B. Iwanschitz, J. A. Schuler, R. Denzler, V. Nerlich, A. Schuler, ECS Trans. 57 (2013) 73-80.

[13] C. Comminges, Q. Fu, M. Zahid, N. Y. Steiner, O. Bucheli, Electrochim Acta 59 (2012) 367-375.

[14] M. Lang, C. Auer, A. Eismann, G. Schiller, P. Szabo, ECS Trans. 7 (2007) 85-94.

[15] D. Perednis, Solid State Ionics 166 (2004) 229-239.

[16] Y.-S. Chou, J. W. Stevenson, J.-P. Choi, J. Power Sources 255 (2014) 1-8.

[17] J. F. B. Rasmussen, P. V. Hendriksen, A. Hagen, Fuel Cells 8 (2008) 385-393.

[18] F. Fleischhauer, R. Bermejo, R. Danzer, A. Mai, T. Graule, J. Kuebler, J. Power Sources 273 (2015) 237-243.

[19] L. D. Hinkle, C. F. Mariano, J. Vac. Sci. Technol. A 9 (1991) 2043-2047.

[20] E. Ivers-Tiffée, A. Weber, D. Herbstritt, J. Eur. Ceram. ... 21 (2001) 1805-1811.

[21] C. Westner, M. Lang, R. Geieregger, Proc. 9h Eur. SOFC Forum B1015 (2010) 114-120.

[22] B. Shaffer, J. Brouwer, J. Fuel Cell Sci. Technol. 9 (2012) 041012.

[23] M. Lang, C. Auer, A. Eismann, P. Szabo, N. Wagner, Electrochim. Acta 53 (2008) 7509-7513.

[24] R. R. Mosbæ k, J. Hjelm, R. Barfod, P. V. Hendriksen, Proc. 11th Eur. SOFC SOE Forum A0902 (2014) 14-22.

[25] S. Primdahl, M. Mogensen, J. Electrochem. Soc. 145 (1998) 2431.

[26] S. Primdahl, M. Mogensen, Proc. 5th Int. Symp. Solid Oxide Fuel Cells V (SOFC- V) 97 (1997) 530-537. 
[27] B. Iwanschitz, Degradation von Ni-Cermet-Anoden in keramischen Hochtemperaturbrennstoffzellen, Ph.D. thesis, Rheinisch -Westfälischen Technische Hochschule Aachen, 2012.

[28] A. Momma, Y. Kaga, K. Takano, K. Nozaki, A. Negishi, K. Kato, T. Kato, T. Inagaki, H. Yoshida, K. Hosoi, Solid State Ionics 174 (2004) 87-95.

[29] B. Liu, H. Muroyama, T. Matsui, K. Tomida, T. Kabata, K. Eguchi, J. Electrochem. Soc. 158 (2011) B215.

[30] J. H. Park, K. Natesan, Oxid. Met. 33 (1990) 31-54.

[31] A. Holt, P. Kofstad, Solid State Ionics 69 (1994) 137-143.

[32] ThyssenKrupp VDM GmbH, Crofer 22 H, Material Data Sheet No. 4050, June Edition, 2010.

[33] Plansee SE, Plansee SE, http://plansee.com/en/CFY-1484.htm, 2014.

[34] P. Huczkowski, N. Christiansen, V. Shemet, L. Niewolak, J. Piron-Abellan, L. Singheiser, W. J. Quadakkers, Fuel Cells 6 (2006) 93-99.

[35] M. Stanislowski, J. Froitzheim, L. Niewolak, W. Quadakkers, K. Hilpert, T. Markus, L. Singheiser, J. Power Sources 164 (2007) 578-589.

[36] T. F. Petersen, Int. J. Thermodyn. 9 (2006) 147-159.

[37] W. C. Chueh, S. M. Haile, Annu Rev Chem Biomol Eng 3 (2012) 313-41.

[38] Cantera, https://code.google.com/p/cantera, 2014.

[39] J. P. Neidhardt, W. G. Bessler, Proc. 10th Eur. SOFC Forum B0502 (2012) 17-24.

[40] M. Linder, T. Hocker, L. Holzer, K. A. Friedrich, B. Iwanschitz, A. Mai, J. A. Schuler, J. Power Sources 272 (2014) 595-605.

[41] A. Momma, K. Takano, Y. Kaga, K. Nozaki, A. Negishi, K. Kato, T. Kato, T. Inajaki, H. Yoshida, K. Hosoi, M. Shibata, M. Yamada, T. Akbay, J. Akikusa, N. Chitose, Proc. Electrochem. Soc. 7 (2005) 554-563.

[42] P. Kofstad, High Temperature Corrosion, Springer, 1988.

[43] Y. Larring, T. Norby, J. Electrochem. Soc 147 (2000) 3251-
3256.

[44] P. Gannon, C. Tripp, A. Knospe, C. Ramana, M. Deibert, R. Smith, V. Gorokhovsky, V. Shutthanandan, D. Gelles, Surf. Coat. Tech. 188-189 (2004) 55-61.

[45] Z. Yang, G.-G. Xia, G. D. Maupin, J. W. Stevenson, Surf. Coat. Tech. 201 (2006) 4476-4483.

[46] S. Megel, E. Girdauskaite, V. Sauchuk, M. Kusnezoff, A. Michaelis, J. Power Sources 196 (2011) 7136-7143.

[47] J. A. Schuler, B. Iwanschitz, L. Holzer, M. Cantoni, T. Graule, Proc. 10th Eur. SOFC Forum B0501 (2012) B0506-B0516.

[48] L. Kaufmann, Thermo-mechanisches Verhalten von Brennstoffzellen, Ph.D. thesis, Zurich University of Applied Sciences ZHAW, 2013.

[49] M. Linder, T. Hocker, L. Holzer, K. A. Friedrich, B. Iwanschitz, A. Mai, J. A. Schuler, J. Power Sources 243 (2013) 508-518.

[50] L. C. Baqué, P. S. Jø rgensen, K. V. Hansen, M. Sø gaard, ECS Trans. 57 (2013) 2027-2036.

[51] L. Jin, W. Guan, X. Ma, H. Zhai, W. G. Wang, J. Power Sources 253 (2014) 305-314.

[52] R. J. Kee, H. Zhu, a. M. Sukeshini, G. S. Jackson, Combust Sci Technol 180 (2008) 1207-1244.

[53] S. Campanari, P. Iora, J. Power Sources 132 (2004) 113-126.

[54] K. Takano, S. Nagata, K. Nozaki, A. Monmaa, T. Kato, Y. Kaga, A. Negishi, K. Kato, T. Inagaki, H. Yoshida, K. Hosoi, J. A. Koji Hoshino c, Taner Akbayc, J. Power Sources 132 (2004) 42-51.

[55] W. G. Bessler, S. Gewies, J. Electrochem. Soc. 154 (2007) B548.

[56] M. Hänsel, W. Quadakkers, D. Young, Oxid. Met. 59 (2003) 285-301.

[57] A. Hagen, R. Barfod, P. V. Hendriksen, Y.-1. Liu, S. Ramousse, J. Electrochem. Soc. (2006) 1165-1171.

[58] L. Holzer, B. Iwanschitz, T. Hocker, B. Münch, M. Prestat, D. Wiedenmann, U. Vogt, P. Holtappels, J. Sfeir, A. Mai, T. Graule, J. Power Sources 196 (2011) 1279-1294. 